\title{
Ecologically safe and techno economically efficient reinforced concrete constructions of equal resistance
}

\author{
Dmitriy Mailyan ${ }^{1, *}$, and Liya Mailyan ${ }^{1}$ \\ ${ }^{1}$ Don State Technical University, 344022, Sotsialisticheskaya, 162, Rostov-on-Don, Russian \\ Federation
}

\begin{abstract}
Creation of reinforced concrete constructions of ideally equal resistance is practically impossible, however maximum approximation to such solution should become the main purpose of constructions designing, since it provides for minimal materials consumption.

Changing of total cross section of pre-stressed reinforcement along the span with the purpose of approximation to elements of equal resistance is possible during creation of stepped section of the element.

In particular, the suggested solution allows to closely approximate the ideal beam of equal resistance, at which with decrease of external moment the height of element's cross-section and the area of cross-section of extrastrong pre-stressed reinforcement are also decreased.

In accordance with the existing reinforced concrete construction with the same class of concrete, reinforcement steel and load the suggested one due to more advanced profile is the most economic - the consumption of steel, concrete and weight of the beam are lower in it. This increases the ecological safety of constructions, as well.
\end{abstract}

\section{Introduction}

Taking into consideration that reinforced concrete constructions today and in the nearest future are being the basis of construction the issues of increase of their ecologic safety and techno economical attractiveness are rather pressing [1-5].

It is known that choice of sections of reinforced concrete constructions is carried out by maximum applied load. At that the major part of constructions has unjustified safety margin. It leads to excessive consumption of materials and increase of environmental pollution. Creation of reinforced concrete constructions of ideally equal resistance is practically impossible, however maximum approximation to such solution should become the main purpose of constructions designing, since it provides for minimal materials consumption.

\footnotetext{
Corresponding author: mailyan@,rgsu.ru
} 
One of the known ways of constrictions creation approximating the elements of equal resistance is changing of dimensions of cross sections across the element in accordance with the moment diagram from external loads. For single-span beams, as well as consoles from metal or wood, in this way almost ideal elements of equal resistance could be achieved. In reinforced concrete it is more difficult, however creation of variable section of elements in this case also leads to significant effect $[1,2,3]$.

\section{Literature review}

Ecologically safe and technoeconomically efficient reinforced concrete constructions of equal resistance is a very actually problem of modern building and constructions. A lot of scientists devote their scientific works to this problem. We can see the parts of this theme in the works of F. Bencardino, A. Condello; P. O. Awoyera, J.O. Akinmusuru, J.M. Ndambuki; Ch.K. Kankam, M. Adom-Asamoah; Sung-Won Yoo, Jinkyo F. Choo; DooYeol Yoo, Young-Soo Yoon, N. Banthia; K. Celik, M.D. Jackson, M. Mancio, C. Meral, A.-H. Emwas, P.K. Mehta, P.J.M. Monteiro; J. Wei, C. Meyer; E. Syroka-Korol, J. Tejchman; Gritsada Sua-Iam, N. Makul; Khoa T. Nguyen, N. Ahn, Tuan A. Le, K. Lee; Jerry M. Paris, Justin G. Roessler, Christopher C; M. Aslam, P. Shafigh, Mohd ZJumaat, M.Lachemi; Hanaa K. Alwan Al-Bayati, Prabir Kr. Das, Susan L. Tighe, H.Baaj; Y. Geng, Y. Wang, J. Chen; P. Zhu, X. Qi Mao, W. Qu, Z. Li, Zhongguo J. Ma; T. Proske, S.Hainer, MoienRezvani, Carl-Alexander Graubne; J. Hu, K. Wang, James A. Gaunt; Se J. Choi, Soo-Hwan Kim, Su-Jin Lee, R. Won, Jong-Pil Won; I. Kovacic, V. Zoller; E. Moretti, E.Belloni, F. Agosti; F. Fedorik, M. Malaska, R. Hannila; A. Haapala; M. Maria Sesana, M.Grecchi, G. Salvalai, C. Rasica; C. Thomas, J. Setién, J.A. Polanco; M. Nematzadeh, A. Salari, J. Ghadami, M. Naghipour; Y. Xing, Q. Han, J. Xu, Qi Guo, Y. Wang, P. Li, Yu-Fei Wu; J. Yin, W. Wang, Z. Man, S. Khoo; R.R. Bhargava, S. Hasan; C. Xue, An He, H. Yong, Y. Zhou; M.V. Menshykova, O.V. Menshykov, Vita A. Mikucka, Igor A. Guz; R.K. Joki, F. Grytten, B. Hayman, B.F. Sorensen; Di-Hua Tong, Xue-Ren Wu; M. El-Zeghayar, T.H. Topper, K.A. Soudki; Doo-Ho Cho, An-Dong Shin, Nam-Su Huh, Hyun-Ik Jeon; C. Fischer, C. Schweizer, T. Seifert at their articles : Eco-friendly external strengthening system for existing reinforced concrete beams [1]; Green concrete production with ceramic wastes and laterite [2]; Strength and ductility characteristics of reinforcing steel bars milled from scrap metals [3]; Evaluation of the flexural behavior of composite beam with inverted-T steel girder and steel fiber reinforced ultra high performance concrete slab [4]; Predicting the post-cracking behavior of normal- and highstrength steel-fiber-reinforced concrete beams [5]; High-volume natural volcanic pozzolan and limestone powder as partial replacements for portland cement in self-compacting and sustainable concrete [6]; Improving degradation resistance of sisal fiber in concrete through fiber surface treatment [7]; Experimental investigations of size effect in reinforced concrete beams failing by shear [8]; Utilization of coal- and biomass-fired ash in the production of self-consolidating concrete [9]; Theoretical and experimental study on mechanical properties and flexural strength of fly ash-geopolymer concrete [10]; A review of waste products utilized as supplements to Portland cement in concrete [11]; Benefits of using blended waste coarse lightweight aggregates in structural lightweight aggregate concrete [12]; Evaluation of various treatment methods for enhancing the physical and morphological properties of coarse recycled concrete aggregate [13]; Time-dependent behaviour of steel tubular columns filled with recycled coarse aggregate concrete [14]; Investigation of using recycled powder from waste of clay bricks and cement solids in reactive powder concrete [15]; Eco-friendly concretes with reduced water and cement contents - Mix design principles and laboratory tests [16]; Recycling lead-based paint contaminated deconstructed masonry materials as aggregate for Portland cement concrete- 
A cost effective and environmental friendly approach [17]; Mix proportion of eco-friendly fireproof high-strength concrete [18]; Building life cycle optimization tools for early design phases [19]; Innovative mineral fiber insulation panels for buildings [20]; Thermal and acoustic characterization Original [21]; Improving the thermal performance of concretesandwich envelopes in relation to the moisture behaviour of building structures in boreal conditions [22]; Methodology of energy efficient building refurbishment: Application on two university campus-building case studies in Italy with engineering students [23]; Structural recycled aggregate concrete made with precast wastes [24]; Experimental and numerical study on static behavior of elastic concrete-steel composite beams [25]; High resolution analysis of opening and sliding in fatigue crack growth[26]; Stress-strain behavior of freshly compressed concrete under axial compression with a practical equation [27]; Experimental and numerical study on static behavior of elastic concrete-steel composite beams [28]; Stress-strain behavior of actively and passively confined concrete under cyclic axial load [29]; Modeling and analysis of gear tooth crack growth under variable-amplitude loading [30]; Crack-tip-opening displacement for four symmetrically situated cracks with coalesced interior yield zones [31]; Crack tip opening displacement in a linear strain hardening material [32]; Interface cracks with initial opening under harmonic loading [33]; Determination of a cohesive law for delamination modelling - Accounting for variation in crack opening and stress state across the test specimen width; Analysis of crack opening stresses for center- and edge-crack tension specimens; A model of crack opening stresses in variable amplitude loading using smooth specimen fatigue test data for three steels; Engineering estimates of crack opening displacement for non-idealized circumferential through-wall cracks in pipe [34]; A crack opening stress equation for inphase and out-of-phase thermomechanical fatigue loading [35].

\section{Ecologically safe and techno economically efficient reinforced concrete constructions of equal resistance}

In this case the most probable solutions include reinforced concrete beams with inclined upper or lower edges, double-wedge section, with curvilinear edges, oval profile, with stepped edges, etc. In reinforced concrete elements changing of the bearing capacity of various sections could be achieved also by way of changing of longitudinal reinforcement which is carried out by creation of interruptions of parts of fixtures or changing on some parts of the class and (or) diameter of one fixture to another with connection of them by jam welding.

Changing of bearing capacity of cross sections of reinforced concrete beams across their span with mixed reinforcing when preliminary tensioning is applied not to all extra-strong fixture but to only part of it is achieved by interruptions of non-stressed parts of reinforcement.

In the beams where all longitudinal reinforcement is pre-stressed, interruptions of its part in the span in the existing solutions are not provided for, which leads to excess margin of safety and cracking resistance on weakly loaded parts of single span bending elements $[4,5]$.

Changing of total cross section of pre-stressed reinforcement along the span with the purpose of approximation to elements of equal resistance is possible during creation of stepped section of the element.

With the purpose of significant decrease of extra-strong steel consumption, as well as concrete, a new design solution is suggested, in which the beam has a stepped profile allowing to interrupt stressed reinforcement in the span in accordance with the materials' curve. Such a solution allows to maximally approximate the beam of equal resistance.

In the solutions suggested, unlike in typical ones, combined pre-stress is taken, in which 
extra-strong reinforcement of the stretched zone is pre-stretched, and compressed zone is pre-compressed. It allows not only to increase cracking resistance of the stretched zone, but also increase tension in the reinforcement of the compressed zone before deformation of compressed concrete to values $R_{s c}+d \sigma_{s p^{\prime}}^{\prime}$.

Reinforced concrete beam has concrete steps creating stepped profile. Interrupted prestressed reinforcement is anchored in concrete steps of the beam with stepped profile. Pretension effort from the cuddy to the reinforcement is translated via inventory pull rods, and initial force is translated the same way, but through rigid inserts. Anchoring of prestressed reinforcement is carried out by collet closing mechanisms.

The beam is manufactured as usual - assembly of reinforcement cage, its installation and fastening in the form - frame, beam casting, transfer of pre-stress from the reinforcement to the concrete to reach the transfer strength by the concrete, beam stripping.

To receive certain technical and economic data of the proposed solution and compare with typical beams the latter have been re-designed in accordance with the indicated proposal. For comparison a typical pre-stressed reinforced concrete I-pile beam with parallel chords - serie 1.462.1 - 1/88. Longitudinal reinforcement of typical beam along the whole length. Main working pre-stressed reinforcement - 4Ø20, A1000 heavy-weight concrete class B30.

Evaluation of efficiency of reinforcement use could be carried out with the help of determination of coefficient, equal to ratio of the area of moments' curve from external forces to the area of the moments' curve from internal efforts (materials' curve) for the suggested beam and the typical one, equal to $=\mathrm{Am} / \mathrm{Abn}$. In the ideal beam of equal resistance this ratio equals 1 . In the actual beams it is less than 1 . With its decrease the efficiency of beam materials use, in particular, of the reinforcement, is decreased.

In the typical reinforced concrete beam, as well as in other reinforced concrete beams with parallel edges and pre-stressed reinforcement, the cross-section of which along the beam is constant, the coefficient of the reinforcement use is minimal, in the reviewed beam it isn $=0.58$. Its value could be significantly increased with the help of interruptions of prestressed reinforcement in the span of the beams with stepped profile. The suggested beam of stepped profile with combined pre-stress with full satisfaction of all technical requirements at the same time has the best economic values.

In the beams with interruptions of longitudinal pre-stressed reinforcement in the stretched and compressed zones the coefficient of reinforcement use efficiency isn $=0.8$.

Consumption of longitudinal extra-strong reinforcement in the stretched and compressed zones in comparison to typical solution is decreased by $12.5 \%$. Total consumption of longitudinal reinforcement decreases by $18 \ldots 21 \%$.

Results of calculations of the typical and suggested beams with the span of $12 \mathrm{~m}$, reviewed above, show that ratio of the moment accepted by the cross-section to the moment from the external load $\mathrm{Ms} / \mathrm{Mon}$ drawing nearer from the average cross-section of the single span beam to the support in the suggested beam increases in the substantially lower degree, than in the typical one. It is related also to the ratio of cracks formation moment $M c k c$ to the external moment $M$.

In particular, the suggested solution allows to closely approximate the ideal beam of equal resistance, at which with decrease of external moment the height of element's crosssection and the area of cross-section of extra-strong pre-stressed reinforcement are also decreased. In the modern construction ribbed reinforced concrete slab roofs are rather widely used. These are mainly slabs with cross-section of flat roof with webs on axial edges in which with rather big spans, as a rule, extra-strong pre-tensioned reinforcement is located. Another type of reinforced concrete slab roofs is two-console slabs of the doubleT type. In the latter axial edges are located $1 / 4$ of the width of the slab from the edges of the slab. At that console corbels of flat flanges are lessening the load of span cross-sections 
which makes the reinforcement of the flange easier.

Main working longitudinal reinforcement located in the longitudinal edges at its prestressing is stretched along the whole span- from one edge to the other. Reinforcement calculated by the highest bending moment in the middle of the span, at the near-support parts of single span slabs turns out to be more necessary, and pre-stress of these parts could lead to destruction of ends and opening of cracks on the upper backs. At that excess safety margin and cracking resistance are created on these parts.

For creation of more economic slabs approximating the elements of equal resistance it is suggested to use the same principle as in pre-stressed beams. With the purpose of decreasing of consumption of the expensive deficit reinforcement it is recommended to create stepped profile of longitudinal edges of slabs, which allows to interrupt pre-stressed reinforcement in the span in accordance with the curve of internal efforts (materials' curve) and anchor it in the steps of stepped profile.

For quantitative evaluation of efficiency of the suggested solutions of reinforced concrete pre-stressed slabs a full calculation of slabs of the suggested construction on both groups of limit states taking into consideration peculiarities related to stepped profile of elements and variable pre-stress gain along the span has been carried out.

It should be noted that bowing of certain elements across the span are changed not only because of changes of values of bending moments, but also in relation to changes in the height of element's cross-section, area of reinforcement cross-section and clamping force. Sags, cracks formation moments and width of cracks opening were determined with consideration to actual characteristic of each cross-section.

With practically equal technical characteristic in the suggested solutions the economic values are higher than in the typical slab. Consumption of extra-strong reinforcement classA 1000 is by $8 . . .9 \%$ less, and slab weight is by $120 \ldots 125 \mathrm{~kg}$ less than in the typical slab. Re-designing of pre-stressed two-console reinforced concrete double-T slabs with the span of $12 \mathrm{~m}$ with wire-rope reinforcement based on the suggested principle allowed to obtain even bigger technical-economic effect compared with traditional solution.

In the reviewed slab the existing traditional solution is that main longitudinal working reinforcement in each of two edges is pre-tensioned. In the suggested solution reinforcing and pre-stressing are assumed as the same, however, pre-stressed reinforcement of the stretched zone, unlike the existing solutions, is interrupted in the span of two cross-sections in accordance with the moments' curve. Both types of two console slabs are designed to evenly distributed load.

\section{Conclusions}

Comparison of technical-economic indices of double-console pre-stressed reinforced concrete traditional and suggested slabs has shown the absolute advantage of the latter. As well as in other previously reviewed types of constructions, creation of conditions approximating the elements to the construction of equal resistance substantially increases their economic efficiency. In this case the economy of extra-strong reinforcement by $14 \%$ is achieved and substantial increase of coefficient of use of working reinforcement.

Positive factor in the suggested solution is also spreading of efforts of concrete clamping transferred to the edges of the construction. Unlike traditional solutions in the suggested one the clamping force is transferred not on the one end section, but on the ends of every part of stepped profile of the construction.

In accordance with the existing reinforced concrete construction with the same class of concrete, reinforcement steel and load the suggested one due to more advanced profile is the most economic- the consumption of steel, concrete and weight of the beam are lower in it. This increases the ecological safety of constructions, as well. 


\section{References}

1. F. Bencardino, A. Condello, Composites Part B: Engineering, 93, 163-173 (2016)

2. P. O. Awoyera, J.O. Akinmusuru, J. M. Ndambuki, Construction and Building Materials, 117, 29-36 (2016)

3. Ch. K. Kankam, M. Adom-Asamoah, Materials \& Design, 23, 537-545 (2002)

4. Sung-Won Yoo, Jinkyo F. Choo, Engineering Structures, 118, 1-15 (2016)

5. Doo-Yeol Yoo, Young-Soo Yoon, N. Banthia, Construction and Building Materials, 93, 477-485 (2015)

6. K. Celik, M.D. Jackson, M. Mancio, C. Meral, A.-H. Emwas, P.K. Mehta, P.J.M. Monteiro, Cement and Concrete Composites, 45, 136-147 (2014)

7. J. Wei, C. Meyer, Applied Surface Science, 289, 511-523 (2014)

8. E. Syroka-Korol, J. Tejchman, Engineering Structures, 58, 63-78 (2014)

9. Gritsada Sua-Iam, N. Makul, Journal of Cleaner Production, 100, 59-76 (2015)

10. Khoa T. Nguyen, N. Ahn, Tuan A. Le, K. Lee, Construction and Building Materials, 106, 65-77 (2016)

11. Jerry M. Paris, Justin G. Roessler, Christopher C., Journal of Cleaner Production, 121, 1-18 (2016)

12. M. Aslam, P. Shafigh, Mohdz Jumaat, M. Lachemi, Journal of Cleaner Production, 119, 108-117 (2016)

13. Hanaa K. Alwan Al-Bayati, Prabir Kr. Das, Susan L. Tighe, H. Baaj, Construction and Building Materials, 112, 284-298 (2016)

14. Y. Geng, Y. Wang, J. Chen, Journal of Constructional Steel Research, 122, 455-468 (2016)

15.P. Zhu, X. Qi Mao, W. Qu, Z. Li, Zhongguo J. Ma, Construction and Building Materials, 113, 246-254 (2016)

16. T. Proske, S. Hainer, M. Rezvani, Carl-Alexander Graubner, Cement and Concrete Research, 51, 38-46 (2013)

17. J. Hu, K. Wang, James A. Gaunt, Conservation and Recycling, 54, 1453-1460 (2010)

18. Se J. Choi, Soo-Hwan Kim, Su-Jin Lee, R. Won, Jong-Pil Won, Construction and Building Materials, 38, 181-187 (2013)

19. I. Kovacic, V. Zoller, Energy, 92, 409-419 (2015)

20. E. Moretti, E. Belloni, F. Applied Energy, 169, 421-432 (2016)

21. F. Fedorik, M. Malaska, R. Hannila, A. Haapala, Energy and Buildings, 107, 226-233 (2015)

22. M. Maria Sesana, M. Grecchi, G. Salvalai, C. Rasica, Journal of Building Engineering, 6, 54-64 (2016)

23. C. Thomas, J. Setién, J.A. Polanco, Construction and Building Materials, 114, 536-546 (2016)

24. M. Nematzadeh, A. Salari, J. Ghadami, M. Naghipour, Construction and Building Materials, 115,402-423 (2016)

25. Y. Xing, Q. Han, J. Xu, Qi Guo, Y. Wang, Journal of Constructional Steel Research, 123, 79-92 (2016)

26. P. Li, Yu-Fei Wu, Composite Structures, 149, 369-384 (2016)

27. J. Yin, W. Wang, Z. Man, S. Khoo, Mechanical Systems and Signal Processing, 40, 105-113 (2013)

28. R.R. Bhargava, S. Hasan, Applied Mathematical Modelling, 36, 5741-5749 (2012)

29. C. Xue, An He, H. Yong, Y. Zhou, Mechanics of Materials, 66, 21-34 (2013)

30. M.V. Menshykova, O.V. Menshykov, Vita A. Mikucka, Igor A. Guz, Composites Science and Technology, 72, 1057-1063 (2012) 
31. R.K. Joki, F. Grytten, B. Hayman, B.F. Sorensen, Composites Science and Technology, 128, 49-57 (2016)

32. Di-Hua Tong, Xue-Ren Wu, Chinese Journal of Aeronautics, 27, 291-298 (2014)

33. M. El-Zeghayar, T.H. Topper, K.A. Soudki, International Journal of Fatigue, 33, 13371350 (2011)

34. Doo-Ho Cho, An-Dong Shin, Nam-Su Huh, Hyun-Ik Jeon, Engineering Fracture Mechanics, 142, 236-254 (2015)

35. C. Fischer, C. Schweizer, T. Seifert, International Journal of Fatigue, 88, 178-184 (2016) 